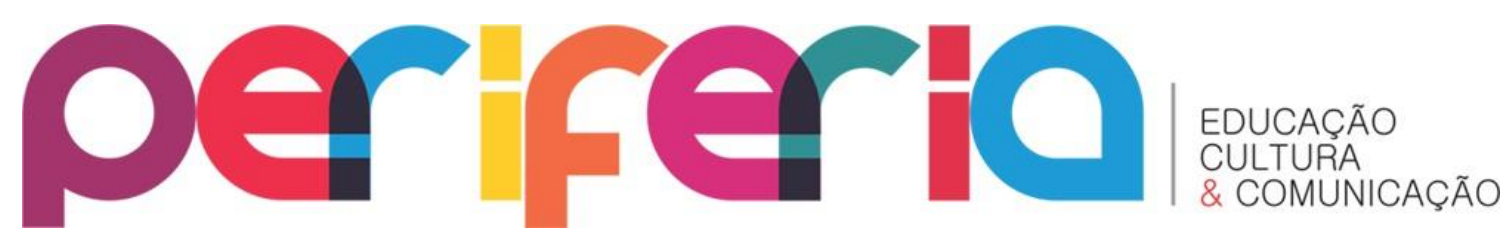

\title{
REDES DE SABERES: PENSAMENTO INTERDISCIPLINAR
}

Marcus Alexandre de Pádua Cavalcanti ${ }^{1}$

\section{RESUMO}

A importância de estruturar diferentes ciências sob a perspectiva de redes mostra que saberes teóricos e práticos podem conviver em um mesmo ambiente, se influenciando mutuamente. 0 fenômeno que a princípio parece objeto de estudo de apenas uma ciência também pode ser estudado por outras. Modificações e influências mútuas ocorrem quando diferentes modalidades de conhecimentos convivem em um mesmo trabalho. É marcante na educação contemporânea a presença do saber compartimentado. Não se estabelece conexão entre as disciplinas e essas são apresentadas aos estudantes como conhecimentos apartados uns dos outros, criando barreiras para uma concepção do conhecimento como um todo. A educação interdisciplinar tem sido a medida de maior recorrência para superar essa fragmentação do saber. A crítica à fragmentação das ciências contemporâneas traz várias discussões epistemológicas acerca da complexidade e dos paradigmas do conhecimento e, nessa perspectiva, busca expor as implicações de uma tentativa de se derivar um pensamento a partir da filosofia de Deleuze, que se configura como uma prática rizomática, em contraponto ao modelo epistemológico arbóreo cartesiano.

Palavras-chave: rede; interdisciplinaridade; conhecimento.

\section{KNOWLEDGE NETWORKS: INTERDISCIPLINARY THINKING}

\section{ABSTRACT}

The importance of structuring various sciences from the perspective of networks shows that theoretical and practical knowledge can coexist in the same environment, are mutually influencing. The phenomenon that at first seems the object of study of only one science can also be studied by others. Modifications and mutual influences occur when different types of knowledge coexist in the same work. It is striking in contemporary education the presence of knowledge compartmentalized. No connection is established between disciplines and these are presented to students as knowledge apart from each other, creating barriers to a

\footnotetext{
${ }^{1}$ Graduado e Especialista em Filosofia - Mestrando Bolsista da CAPES do Programa de Pós-Graduação em Letras e Ciências Humanas - UNIGRANRIO. marcus_nathan1203@homail.com
} 


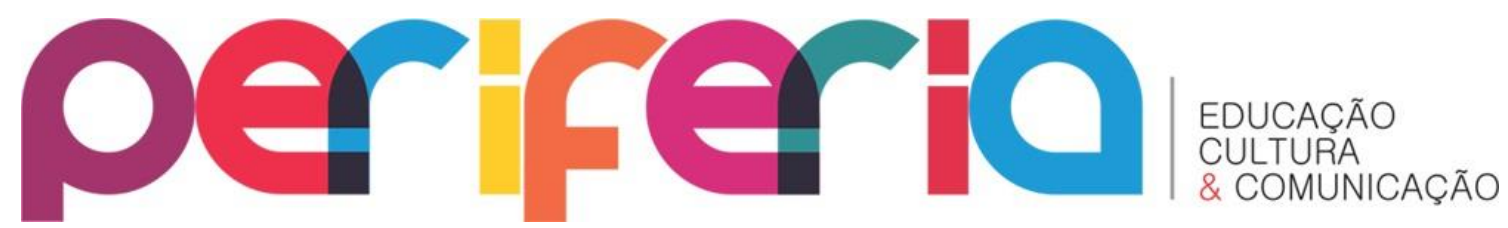

conception of knowledge as a whole. The interdisciplinary education has been the measure of higher recurrence to overcome this fragmentation of knowledge. The criticism of the fragmentation of contemporary science brings several epistemological discussions about the complexity and paradigms of knowledge and, in this perspective, seeks to expose the implications of an attempt to derive a thought from the philosophy of Deleuze, which is configured as a rhizomatic practice as opposed to the cartesian epistemological model tree

Keywords: network; interdisciplinarity; knowledge.

\section{Introdução}

O paradigma mecanicista, que surgiu na modernidade clássica com René Descartes tem seu início nos meados do século XVII, e promoveu o que entendemos hoje por compartimentarização do conhecimento, em que o conteúdo é tratado em sua forma fragmentada, dividida e separada da complexidade da realidade. Isso deu origem à especialização do conhecimento e, consequentemente, ao formato disciplinar da educação que conhecemos.

No interior do modelo de educação, é marcante a presença do saber compartimentado. As disciplinas não se conectam umas as outras e são apresentadas aos estudantes como conhecimentos apartados uns dos outros, criando barreiras para que os discentes experimentem uma concepção do conhecimento como um todo.

A contemporaneidade tem motivado o surgimento de teorias educacionais que privilegiam uma abordagem direcionada para a interconexão de saberes, estes oriundos de diversas esferas do conhecimento, desenvolvendo-se assim, um processo educacional voltado para a chamada interdisciplinaridade. Este constante diálogo entre as disciplinas pode ser então encarado sob diversos níveis que se diferenciam no modo e na intensidade que determinados conhecimentos irão traçar sua linha de relação e interação.

A educação interdisciplinar tem sido a medida mais corrente para superar essa fragmentação do saber. Como resposta a tal problema, tem-se mencionado sobre a proposta de uma pedagogia rizomática, a partir de comentários em torno do pensamento de Gilles Deleuze, filósofo francês que não dedicou obras diretamente ligadas a questões educacionais, mas que ofereceu bases para isso, principalmente ao criticar o modelo de conhecimento 


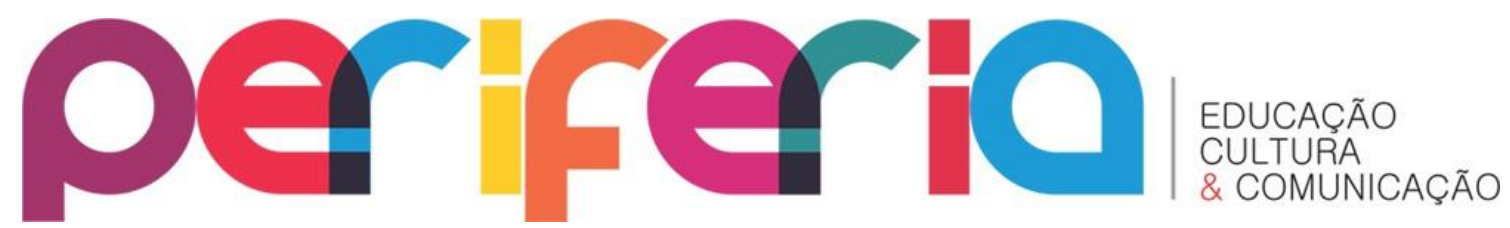

baseado na estrutura arbórea. Como contraponto e alternativa à metáfora da árvore, Deleuze lança, no campo de produção do conhecimento, a noção de rizoma. O conceito de rizoma surge, assim, em Deleuze e Guattari, em oposição à forma segmentada de se conceber a realidade, bem como ao modo positivista de se construir conhecimento.

\section{A modernidade e o pensamento fragmentado}

[...] o fenômeno da hiperespecialização faz com que um verdadeiro mosaico [...] de objetos, cerrados, fechados, disciplinares não possam se comunicar uns com os outros [...] nessa especialização produz-se outro fenômeno, que é a fragmentação [...], que leva à perda de visão da realidade como um todo complexo. (MORIN, 2000, p. 23)

No decorrer da história do Ocidente, é possível vislumbrar a subordinação do múltiplo pelo uno como uma característica marcante, onde o uno sempre esteve contido no múltiplo. Além disso, muitas vezes, na história, o múltiplo só foi admitido para garantir o uno por oposição dialética. O pensamento binário produziu a metafísica, colocando a transcendência em um lugar privilegiado em relação à imanência. Desde os tempos da Grécia antiga vivemos pensando por oposição, separação, conceituação e classificação. Dentro dessa perspectiva o esquema arborescente de Platão é até hoje utilizado como "paradigma" em diversas áreas do saber.

No período moderno, com a "invenção da ciência" (STENGERS, 2001), passa-se a priorizar a purificação dos saberes. Tudo o que pode ganhar estatuto de verdade deve ser quantificado e classificado dentro de um campo determinado do saber. As polarizações que advêm deste movimento (sujeito-objeto, homem natureza) se dão por uma sobreposição do racional ao corpóreo, assim como pela cientificização e objetivação da compreensão do mundo. Esta característica Ocidental de separação e de compartimentarização se estendeu a todas as instâncias das vidas, portanto ela esteve presente desde a organização arquitetônica de uma casa, até a organização do pensamento. A lógica central tanto da árvore quanto da radícula foi sempre remeter-se a uma unidade conceitual, classificatória e reducionista. $A$ 


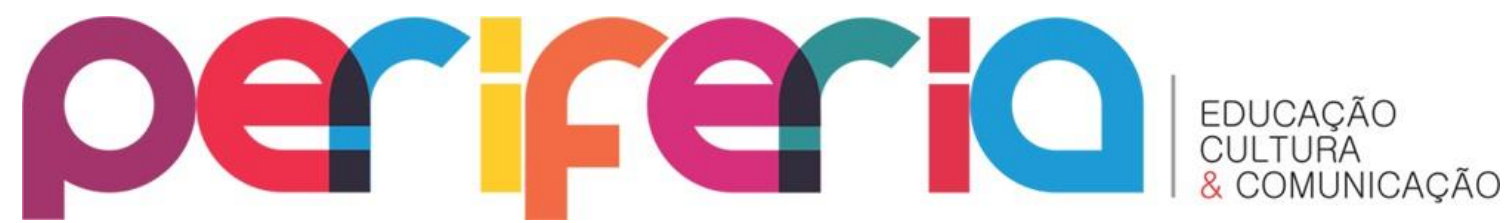

própria noção de indivíduo é uma idéia segmentada, assim como a divisão entre sujeito e objeto.

Somos segmentarizados por todos os lados e em todas as direções. O homem é um animal segmentário. A segmentaridade pertence a todos os estratos que nos compõe. Habitar, circular, trabalhar, brincar: o vivido é segmentarizado espacialmente e socialmente. A casa é segmentarizada conforme a destinação de seus cômodos; as ruas, conforme a ordem da cidade; a fábrica, conforme a natureza dos trabalhos e das operações (DELEUZE; GUATTARI, 2000, p. 84)

A crença de que esse modelo produziria maior objetividade às análises fez com que a ciência fosse altamente valorizada na modernidade, por se crer em sua neutralidade, gerando uma crença correlata em seu descompromisso político. A purificação do mundo foi um empreendimento da modernidade que até hoje tem reflexos em nossos corpos e nossas vidas. Da modernidade herdamos a fé de que somos independentes das coisas que produzimos e que os juízos científicos são realmente verdadeiros, pois sua objetividade faz com que um fato venha à tona. A maioria dos métodos de pesquisas, nessa época, tem um caráter quantitativo que visava justamente à classificação (e a hierarquização), a conceituação (logo a busca da identidade), reforçando a crença de que o pesquisador pode ser neutro em relação ao estudo que realiza.

O conhecimento é colocado, classicamente, sob a metáfora da árvore. Sob o modelo arbóreo, as certezas de onde devem partir todo o conhecimento (inclusive no sentido propriamente cartesiano) são identificadas às raízes, de onde se ergue o tronco (portanto, o próprio conhecimento). Um tronco precisa ser firme, pois se ergue sobre premissas irrefutáveis, daí se ramifica todas as áreas do conhecimento, todos os "galhos". Silvio Gallo nos oferece uma problemática dessa metáfora, demonstrando como o processo arborescente do conhecimento, leva, da raiz ao galho, às especializações do conhecimento:

O tronco da 'árvore do saber' seria a própria Filosofia, que originalmente reuniria em seu seio a totalidade do conhecimento; com o crescimento progressivo da árvore, adubada intensamente 


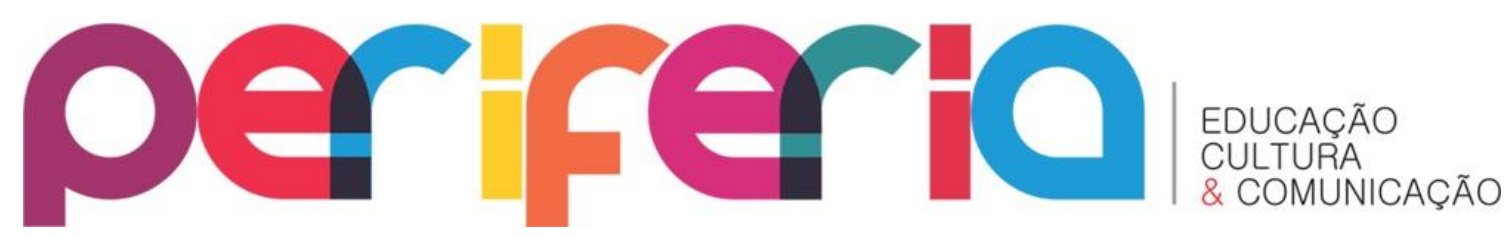

pela curiosidade e pela sede de saber própria do ser humano, ela começa a desenvolver os galhos das mais diversas 'especializações' que, embora mantenham suas estreitas ligações com o tronco nutrem-se de sua seiva e a ele devolvem a energia conseguida pela fotossíntese das folhas em suas extremidades, num processo de mútua alimentação/fecundação - apontam para as mais diversas direções, não guardando entre si outras ligações que não sejam o tronco comum, que não seja a ligação história de sua genealogia. Para ser mais preciso, as ciências relacionam-se todas com seu 'tronco comum' - pelo menos no aspecto formal e potencialmente -, embora não consigam, no contexto desse paradigma, relacionar-se entre si. (GALLO, 2008, p.73)

Se desejamos pensar de fato a possibilidade de uma educação não-disciplinar, é necessário que tentemos visualizar o conhecimento e seu processo de construção de outra maneira. Tradicionalmente, usamos a metáfora da árvore para compreender o campo dos vários saberes. O paradigma arbóreo implica uma hierarquização do saber, como forma de mediatizar e regular o fluxo de informações pelos caminhos internos da árvore do conhecimento. A frondosa árvore que representa os saberes apresenta-os de forma disciplinar: fragmentados (os galhos) e hierarquizados (os galhos ramificam-se e não se comunicam entre si, a não sei que passem pelo tronco).

Embora seja uma metáfora botânica, o paradigma arborescente representa uma concepção mecânica do conhecimento e da realidade, reproduzindo a fragmentação cartesiana do saber, resultado das concepções científicas modernas.

Os sistemas arborescentes são sistemas hierárquicos que comportam centros de significação e de subjetivação, autômatos centrais, assim como memórias organizadas. Os modelos correspondentes são aqueles em que um elemento não recebe suas informações senão de uma unidade superior, e uma afetação subjetiva, de ligações preestabelecidas. Isso fica claro nos problemas atuais da informática e das máquinas eletrônicas, que conservam ainda o mais velho pensamento, na medida em que confere o poder a uma memória ou a um órgão central. (DELEUZE; GUATTARI, 2000, p.25)

Revista Periferia, v.10, n.1, p. Xx - xx, Jan./Jun. 2018 


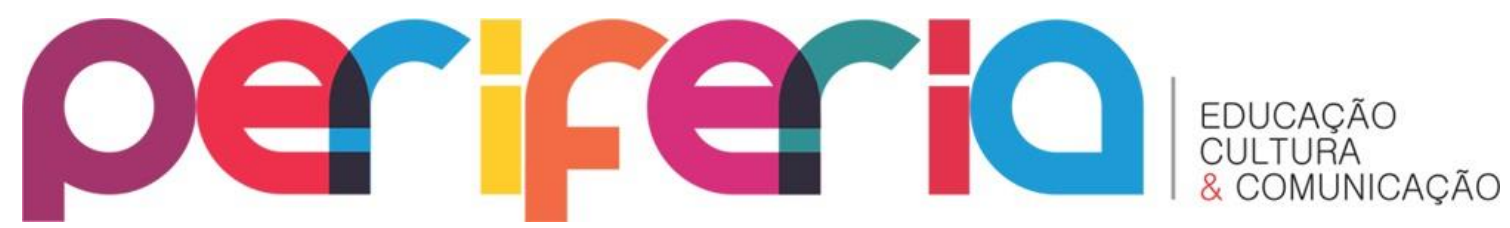

Esse modo sistemático de produção de conhecimento representa uma forma mecânica de apreensão da realidade, e está ainda impregnado nas bases de grande parte das entidades científicas que ainda hoje dominam os veículos de produção e circulação de saberes. 0 paradigma mecanicista, que surgiu na modernidade clássica com René Descartes, promoveu o que entendemos hoje por compartimentarização do conhecimento, em que o conteúdo é tratado em sua forma fragmentada, dividida e separada da complexidade da realidade. Isso deu origem à especialização do conhecimento e, conseqüentemente, ao formato disciplinar da educação que conhecemos.

Segundo Chalmers (1981), Francis Bacon foi um dos primeiros a articular o que é o método da ciência moderna. Propôs que a meta da ciência é o melhoramento da vida do homem na terra e, para isso, deveria coletar fatos com observação organizada e derivar, a partir daí, novas teorias. Bacon formulou a teoria da indução, que serve para descrever minuciosamente os cuidados, técnicas e procedimentos para a investigação dos processos naturais. A máxima baconiana é: "saber é poder". Assim, para dominar a natureza, é preciso conhecer as leis da natureza por meios comprovados por intermédio de experimentos.

Descartes, vai inequivocadamente, das ideias para as coisas, e não das coisas para as ideias, e estabelece a prioridade da metafísica como fundamento último da ciência. Para Descartes, segundo Santos (2001, p. 63), "as idéias que presidem a observação e a experimentação são as ideias claras e simples a partir das quais se pode ascender a um conhecimento mais profundo e rigoroso da natureza". Essas ideias são as ideias matemáticas. A matemática forneceu para ciência moderna o instrumento de análise, a lógica da investigação e o modelo de representação da própria estrutura da matéria.

O método cartesiano consiste de quatro regras básicas, que, segundo Descartes, são capazes de conduzir o espírito à verdade. Em primeiro lugar, a evidência, o objeto deve ser exposto com clareza; em segundo lugar, a decomposição, é preciso dividir em tantas partes, em quantas forem necessárias; em terceiro, a ordenação, é fundamental partir dos problemas mais simples para os mais complexos; por fim, a revisão, é imperativo fazer as verificações para certificar-se de que nada esteja errado.

O modelo explicativo filosófico cartesiano do mundo, ampara-se na matemática. A valorização da matemática decorre de dois aspectos que a caracterizam. Em primeiro lugar, da 


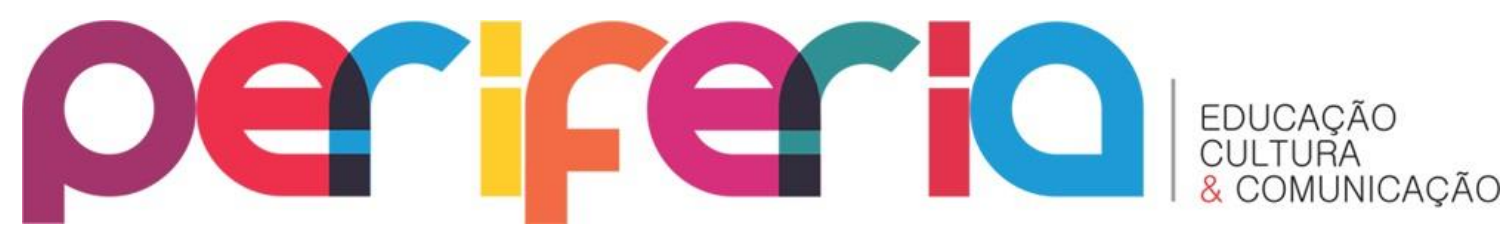

idealidade pura de seus objetos, que não se confundem com as coisas percebidas subjetivamente por nós, são universais e necessárias. Em segundo lugar, em segundo lugar, a decomposição, é preciso dividir em tantas partes, em quantas forem necessárias; em terceiro, a ordenação, é fundamental partir dos problemas mais simples para os mais complexos; por fim, a revisão, é imperativo fazer as verificações para certificar-se de que nada esteja errado.

O primado da individualidade tornou-se o centro de interesse dos valores e do conhecimento. Os desdobramentos do método cartesiano, baseado no princípio das ideias claras e distintas, e a proposição empírica dos fatos e das coisas, ou seja, as "ideias" e as constatações empíricas consolidam o paradigma da ciência moderna. Podemos, a partir de então segundo Santos (2001) falar de um modelo global, isto é, ocidental, de racionalidade científica.

Mas será, de fato, que o pensamento e o conhecimento seguem a estrutura proposta por um paradigma arborescente? Não será tal paradigma um modelo composto posteriormente e sobreposto ao conhecimento já produzido, como forma de abarcá-lo, classificá-lo e, assim, facilitar o acesso a ele e seu domínio, passando mesmo a determinar a estrutura de novos conhecimentos a serem criados? Se assim for, não seria razoável conjeturar que o pensamento procede - ou possa proceder - de outra maneira, menos hierarquizada e mais caótica?

\section{Transformações contemporâneas: pensando com o Rizoma}

Em contrapartida a esse tipo de pensamento, que desemboca em determinada prática, os teóricos Gilles Deleuze e Félix Guattari ao criticar as formas instituídas de compreensão das ciências e manutenção de conhecimentos, engendram um inovador ponto de vista filosófico, tratando com relevante afinco acerca da construção do pensamento, da racionalidade como um todo; propõem então a perspectiva rizomática.

O conceito de rizoma foi cunhado por Gilles Deleuze e Félix Guattari (2000), como resposta à metáfora da árvore que se vai bifurcando e que representa a lógica clássica e os procedimentos binários e dicotômicos. Este conceito foi emprestado da Botânica, que define os sistemas de formações aéreas, ligadas à parte subterrânea de plantas flexíveis, que dão brotos e raízes adventícias na sua parte inferior. Descreve-se o rizoma, recorrendo à imagem 


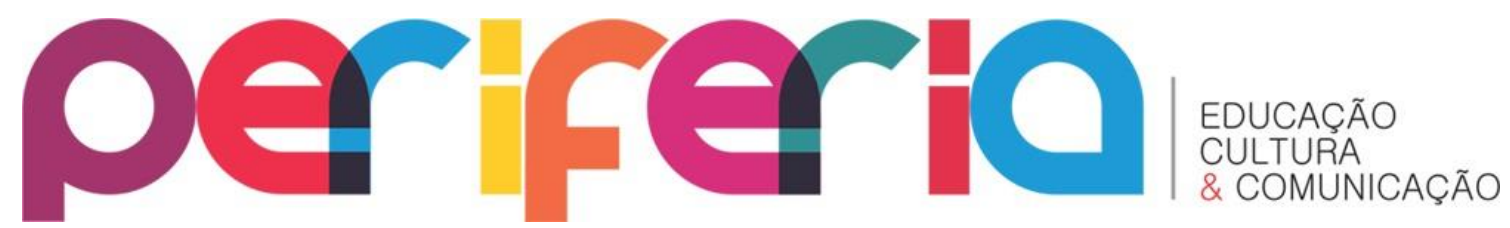

de bulbos e tubérculos de múltiplas ramificações. Serve para designar um modelo semântico oposto às concepções de árvore, com hierarquia, centro e ordem de significação.

Essa, como tese filosófica que é, tem inerente em sua concepção a responsabilidade de explicar o mundo em toda a sua complexidade e vastidão; sugerem os autores para tanto que se tenha uma interpretação em rede, horizontal, dos saberes formando assim um rizoma, uma "raiz" da qual e na qual se entrecruzam e estabelecem diversas conexões, em vários pontos, os temas e as idéias

O que predomina na idéia de rizoma é o descentramento que causa em relação ao modelo predominante de pensamento: o da árvore. Se o rizoma se opõe a árvore, é essencialmente sobre a impossibilidade de ligações diretas no modelo arbóreo, pois toda ligação, aí, necessita de passar pelo tronco, ou seja, toda associação é determinada por um centro. A existência de centros supõe hierarquias, onde o eixo de suporte, ou uma estrutura sobrecodificadora, decalca o que já está dado. A lógica da árvore é, portanto, a lógica do mesmo, "toda lógica da árvore é uma lógica do decalque e da reprodução. [...] A árvore articula e hierarquiza os decalques, os decalques são como folhas da árvore" (DELEUZE; GUATTARI, 2000, p.21). Nesse campo, sempre uma unidade superior determina as conexões estabelecendo-as previamente e dando seu significado. Enquanto que o rizoma, pode ser quebrado "em um lugar qualquer, e também retoma segundo uma ou outra de suas linhas e segundo outras linhas" (DELEUZE; GUATTARI, 2000, p. 18). Não se justifica então, ao contrário da árvore, o assentamento em uma estrutura básica ou em um modelo gerativo. 0 rizoma é "estranho a qualquer idéia de eixo genético ou de estrutura profunda" (DELEUZE; GUATTARI, 2000, p. 21).

O rizoma, diferente da árvore, não se hierarquiza, como não envolve significação prévia e nem pode ser reduzido a uma unidade. O rizoma é sempre múltiplo, e só atua em função de seu agenciamento com outro rizoma, pode ser acessado em múltiplos pontos, segundo sua cartografia. O rizoma é devir, pois "não tem começo nem fim, mas sempre um meio pelo qual ele cresce e transborda" (DELEUZE; GUATTARI, 2000, p. 32).

Deleuze e Guattari dão algumas pistas sobre a produção de um rizoma e fazem isso elaborando princípios, que visam justamente reafirmar a falta de uma configuração prévia. 


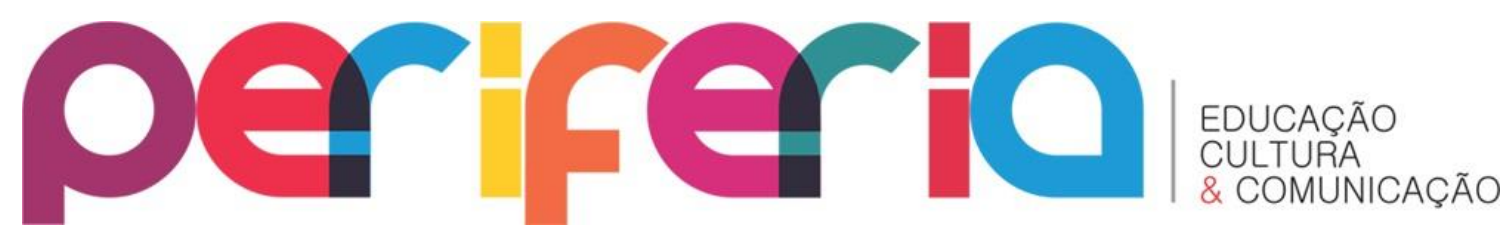

Os princípios do rizoma (DELEUZE; GUATTARI, 2000, p. 17) são:

1 - Principio de conexão e heterogeneidade: qualquer ponto do rizoma pode ser conectado a qualquer outro. A metáfora de árvore ou raiz pressupõe certa ordem, enquanto o princípio aqui referido envolve cadeias semióticas de todo tipo e conectadas a diversos modos de codificação. Um rizoma conecta componentes semióticos de organização de poder que remetem às artes, às ciências e às lutas de classes. Um componente semiótico é como um tubérculo que aglomera diversos atos linguísticos, mas também perceptivos, mímicos, gestuais, cognitivos. Não existe linguagem em si nem universalidade da linguagem. Na linguagem contribuem vários dialetos, pois não existe locutor-auditor ideal nem comunidade linguística homogênea. As entradas de um rizoma são múltiplas, fazendo com que ele seja acentrado e que ele tome qualquer direção e forma. Não existe forma previa, nem determinismos, as conexões são feitas por contágio ou contato.

Num rizoma, ao contrário, cada traço não remete necessariamente a um traço lingüístico: cadeias semióticas de toda natureza são aí conectadas a modos de codificação muitos diversos, cadeias biológicas, políticas, econômicas, etc,..., colocando em jogo não somente regime de signos diferentes, mas também estatuto de estado de coisas. Os agenciamentos coletivos de enunciação funcionam, com efeito, diretamente nos agenciamentos maquínicos, e não se pode estabelecer um corte radical entre os regimes de signos e seus objetos. (DELEUZE; GUATTARI, 2000, p.15)

2 - Princípio de multiplicidade: (termo que os autores preferem ao de múltiplo) cuja inexistência de unidade seria sua característica principal. Assim, na instância da multiplicidade não faz sentido falarmos de sujeito ou de objeto, já que se trata aqui de grandezas e determinações que se expandem de acordo com seus agenciamentos. "Um agenciamento é precisamente este crescimento das dimensões numa multiplicidade que muda necessariamente de natureza à medida que ela aumenta suas conexões." (DELEUZE; GUATTARI, 2000, p.17). As multiplicidades são linhas, nunca pontos fixos. Além disso, só existe uma unidade ou identidade na multiplicidade quando se produz, ou processos de subjetivação, ou processos de significação (desta maneira, dissimulam-se essências). Assim, se de um lado a unidade cria uma sobrecodificação da multiplicidade, produzindo uma dimensão vazia de 


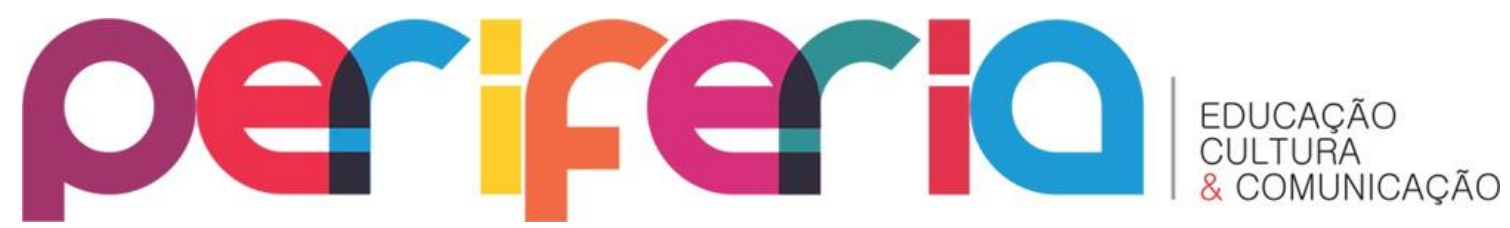

sentido; de outro o rizoma criaria um plano de consistência que está sempre em expansão e movimento, o que não permite que ele seja capturado pela sobrecodificação.

As multiplicidades se definem pelo fora: pela linha abstrata, linha de fuga $^{2}$ ou desterritorialização segundo a qual elas mudam de natureza aose conectarem às outras. (...) As multiplicidades planas a n dimensõessão a-significantes e a-subjetivas. Elas são designadas por artigos indefinidos, ou antes partitivos (DELEUZE; GUATTARI, 2000, pp.17-18)

3 - Princípio de ruptura a-significante: Um rizoma pode ser rompido, quebrado em um lugar qualquer, e também retoma segundo uma ou outra de suas linhas e segundo outras linhas. É como tentar exterminar formigas, rizomas animais: elas reconstróem-se, segundo suas condições de ressurgimento. Um rizoma compreende linhas de segmentaridade segundo as quais ele se estratifica, territorializa, organiza, mas também compreende linhas de desterritorialização pelas quais foge sem parar. Isso não quer dizer que a ruptura necessariamente se liberte da dominação de um significante, da formação de um sujeito. Tudo depende das organizações que reestratificam o novo (ou velho) conjunto. É por isso que o livro não é a imagem do mundo, ele faz rizoma com o mundo, territorializando-se e desterritorializando-se mutuamente. De todo modo, é certo que os processos de desterritorialização e reterritorialização são todos relativos uns aos outros.

4 - Princípio de cartografia e de decalcomania: O método cartográfico é aquele utilizado como o instrumento que vai "fotografar" o acontecimento, tal cartografia nos mostra que ele possui entradas múltiplas; isto é, o rizoma pode ser acessado de infinitos pontos, podendo daí remeter a quaisquer outros em seu território. O paradigma arborescente remete ao mesmo porque toda a lógica da árvore é uma lógica da cópia, da reprodução. O rizoma, porém, enquanto mapa, possui sempre regiões insuspeitas, uma riqueza geográfica pautada numa lógica do devir, da exploração, da descoberta de novas facetas. A decalcomania indica que os mapas podem, no entanto, ser copiados, reproduzidos; colocar uma cópia sobre

\footnotetext{
${ }^{2}$ A linha de fuga marca, ao mesmo tempo, a realidade de um número de dimensões finitas que a multiplicidade preenche efetivamente; a impossibilidade de toda dimensão suplementar, sem que a multiplicidade se transforme segundo esta linha; a possibilidade e a necessidade de achatar todas estas multiplicidades sobre o mesmo plano de consistência ou de exterioridade, sejam quais forem suas dimensões. (DELEUZE \& GUATTARI, 2000, p. 17).
}

Revista Periferia, v.10, n.1, p. xx - xx, Jan./Jun. 2018 


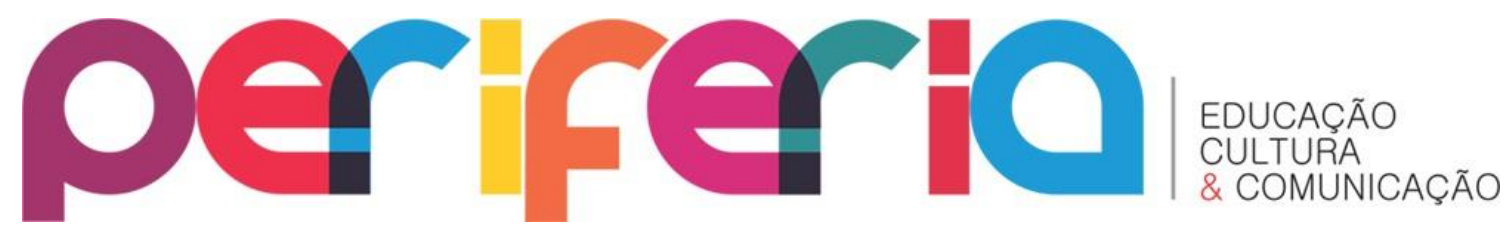

o mapa nem sempre garante, porém, uma sobreposição perfeita. O inverso é a novidade: colocar o mapa sobre as cópias, os rizomas sobre as árvores, possibilitando o surgimento de novos territórios, novas multiplicidades. Por ser da ordem da representação, o decalque precisa isolar o que the serve como modelo e artificialmente organizar, estabilizar, neutralizar as multiplicidades segundo as significâncias e subjetivações que já são suas.

Se pensarmos o conhecimento como rizoma e não como árvore, as disciplinas já não seriam gavetas que não se comunicam, mas tenderiam a soar como linhas que se misturam, teia de possibilidades, multiplicidade de nós, de conexões, de interconexões.

Se a árvore não estimula e mesmo não permite o diálogo, o rizoma, ao contrário, em sua promiscuidade estimula os encontros e as conjunções. Mas se a imagem da árvore implica num sistema fechado e unitário, a imagem do rizoma, por sua vez, implica num sistema aberto e múltiplo. Não um percurso, mas inúmeros percursos. E sempre com pontos de partida e pontos de chegada distintos. O que não inviabiliza encontros mas, ao contrário, os possibilita, os promove, os estimula.

Para Edgar Morin, os saberes tradicionais foram submetidos a um processo reducionista que acarretou a perda das noções de multiplicidade e diversidade.

O sistema educativo fragmenta a realidade, simplifica o complexo, separa o que é inseparável, ignora a multiplicidade e a diversidade... As disciplinas como estão estruturadas só servem para isolar os objetos do seu meio e isolar partes de um todo. Eliminam a desordem e as contradições existentes, para dar uma falsa sensação de arrumação. A educação deveria romper com isso mostrando as correlações entre os saberes, a complexidade da vida e dos problemas que hoje existem. (MORIN, 2003, p.22).

A simplificação, de acordo com Morin, está a serviço de uma falsa racionalidade, que passa por cima da desordem e das contradições existentes em todos os fenômenos e nas relações entre eles. As mentes formadas pelas disciplinas perdem suas aptidões naturais tanto para contextualizar os saberes, quanto para integrá-los em seus conjuntos naturais (MORIN, 


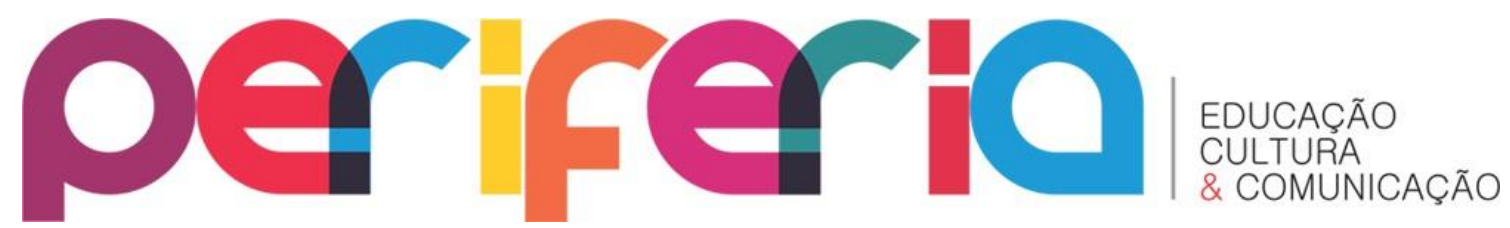

2001). A divisão das disciplinas impossibilita entender o que está tecido junto (idem) ou o complexo, o que precisa ser repensado para que seja possível conceber abordagens mais aproximadas da realidade social.

Para Morin, a necessidade de um pensamento complexo veio da especialização do conhecimento, que teria destruído a multidimensionalidade dos fenômenos na modernidade. Tal complexidade implicaria em uma reorganização das estruturas do saber, através de uma relação circular ativa entre algumas disciplinas da ciência. A proposta epistemológica de Morin propõe a superação de um pensamento simplificador que teria vigorado por toda uma era, no qual a ciência teria se apoderado do objeto e a filosofia do sujeito, através da idealização, racionalização e normalização dos fatos. Seu pensamento possui uma inspiração espiral, de uma radicalidade justificada pela crise social e humana igualmente radicais que experimentamos.

Concordamos totalmente com a avaliação de Morin. E gostaríamos de ir mais além e dizer que, em nossa opinião, a fragmentação que experimentamos na educação é mero reflexo da fragmentação da realidade que permeia a mentalidade do homem moderno, a qual, por sua vez, tem origem no conceito amplamente difundido pelo cientificismo moderno e por alguns ramos da filosofia de que o mundo não tem sentido.

Romper com a disciplinarização, tarefa possível através da adoção de um outro paradigma de saber, como o rizomático que propomos aqui, significa também redesenhar o mapa estratégico do poder no campo da(s) ciência(s) e no campo da educação, colocando as relações numa outra dimensão.

\section{Considerações finais:}

A consciência de estarmos vivendo um tempo marcado por nuances culturais, econômicas e políticas diferentes daquelas que caracterizaram a modernidade e seus pressupostos epistemológicos se faz presente em nós atravessando nossos cotidianos. 


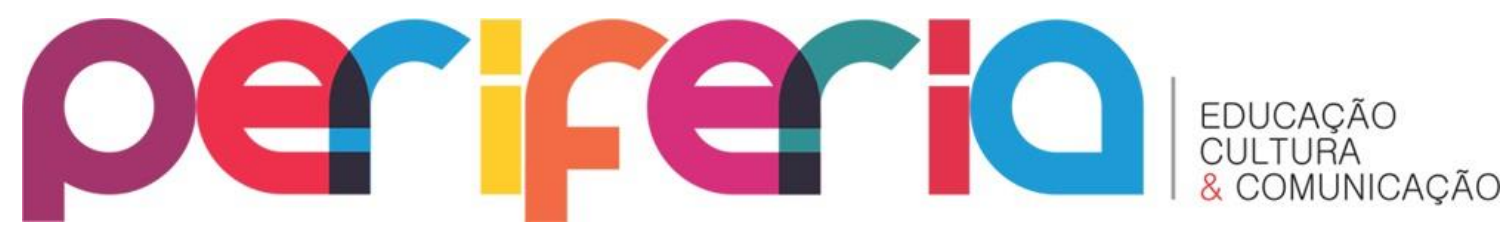

Percebemos que o conhecimento ganha uma dimensão que ultrapassa o limitado campo disciplinar, exigindo novos conceitos e práticas que respondam ao cuidado integral dos sujeitos. Assim, falta a escola pensar esse conhecimento como construção interdisciplinar pautado no aprofundamento teórico que produza práticas e ações interdisciplinares e intersetoriais para responder a complexa variedade de demandas observadas atualmente na educação. Abrir o campo de visão das áreas do conhecimento, negando certezas dogmáticas e isolamentos teóricos em prol da abertura à pluralidade de relações e perspectivas por meio de um olhar mais crítico e reflexivo sobre o mundo e sobre a própria idéia de conhecimento.

No entanto, algumas questões insistem em se repetir: como construir o conhecimento e, sobretudo, como atuar de forma interdisciplinar quando a formação historicamente fragmentou o conhecimento em disciplinas especificas que dialogavam muito pouco entre si? O que fazer com a construção já realizada que supervalorizou a especialidade? De que forma transpor as lacunas do conhecimento interdisciplinar e a linearidade do saber? Num primeiro momento, a inquietação gerada por esses questionamentos cria uma resistência à mudança. $A$ interdisciplinaridade pressupõe acreditar na possibilidade de partilhar o saber explicitando-o, discutindo-o.

É justamente essas inquietações que poderão estimular as potencialidades de mudança do saber linear para o saber interdisciplinar onde o conhecimento é construído por todos de forma colaborativa e participativa. Essa construção individual e, ao mesmo tempo, coletiva possibilitará uma nova percepção do saber do outro, permitindo maior valorização do coletivo em favor do conhecimento.

\section{Referências bibliográficas:}

CHALMERS, Alan. O que é ciência afinal? Brasília: Editora Brasiliense, 1981. 


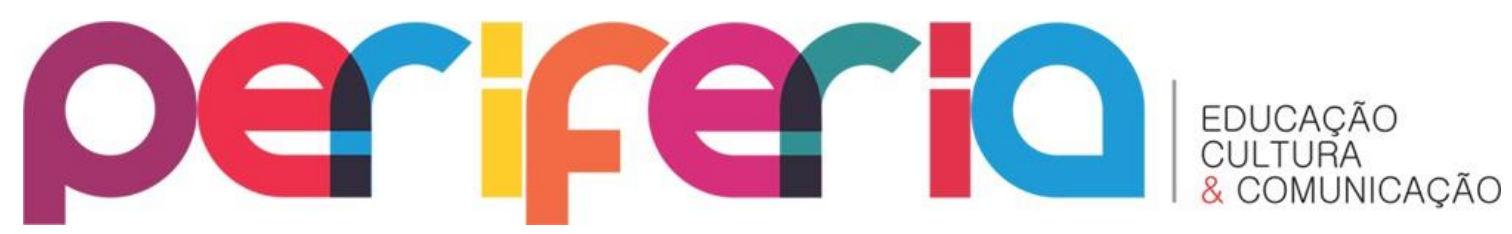

DELEUZE, Gilles; GUATTARI, Felix. Mil Platôs: capitalismo e esquizofrenia. São Paulo:

Editora 34, 2000, (v. 1).

GALLO, Sílvio. Deleuze \& a Educação. Belo Horizonte: Autêntica, 2008.

GUATTARI, Felix. e ROLNIK, Sueli. Notas descartáveis sobre alguns conceitos. In: Micropolítica

- cartografias do desejo. Petrópolis: Vozes, 1986.

MORIN, Edgar. Ciência com consciência . Rio de Janeiro: Bertrand Brasil, 2000.

MORIN, Edgar.; LE MOIGNE, Jean-Louis. A inteligência da complexidade. 3ed. São Paulo: Petrópolis, 2000

MORIN, Edgar. A Escola mata a curiosidade. [dez., 2003]. Entrevistadora: P. Gentili. Nova Escola, São Paulo, edição 168, dez. 2003.

SANTOS, Boaventura de Sousa. Da ciência moderna ao novo senso comum. In: A crítica da razão indolente. Contra o desperdício da experiência. v. 1, 3. ed. São Paulo. Cortez, 2001. p. 55-117.

STENGERS, Isabelle . A Invenção das ciências modernas. São Paulo: Ed. 34, 2001. 
DOI: https://doi.org/10.12957/periferia.2018.12478

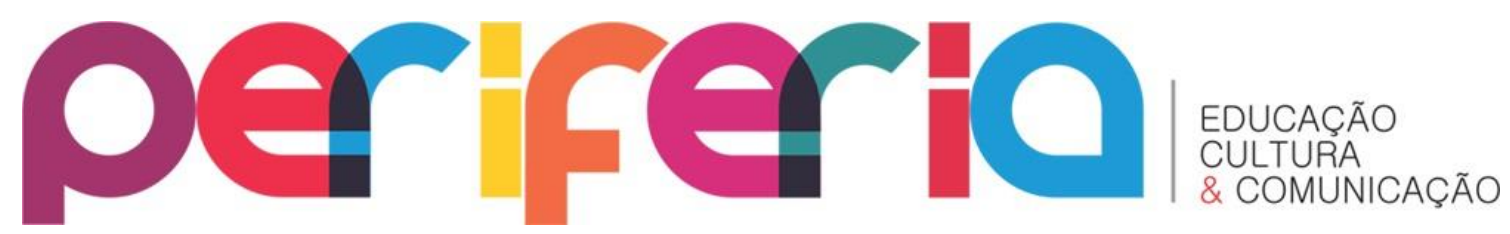

